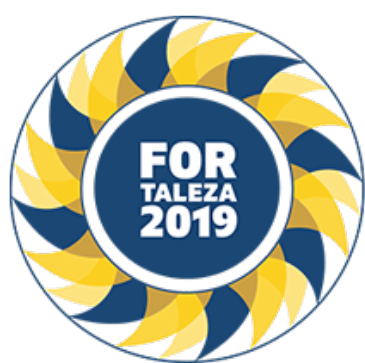

\title{
SYPHILIS AND SECONDARY FOCAL AND SEGMENTAL GLOMERULOSCLEROSIS: A RARE ASSOCIATION
}

Jokasta Nunes Lobo (Hospital Geral de Fortaleza, Fortaleza, CE, Brasil), José Jeová Andrade Neto (Hospital Beneficência Portuguesa, São Paulo, SP, Brasil), Christian Max Uchôa Leite (Hospital Geral de Fortaleza, Fortaleza, CE, Brasil), Frederico Araujo Lima Verde (Hospital Geral de Fortaleza, Fortaleza, CE, Brasil), Samily Cordeiro de Oliveira (Universidade Federal do Ceará, Fortaleza, CE, Brasil), Lysiane Maria

Adeodato Ramos Fontenelle (UNIFOR, Fortaleza, CE, Brasil), Kirla Wagner Poti Gomes (UNIFOR, Fortaleza, CE, Brasil)

\section{BACKGROUND}

Syphilis is a globally known infectious disease whose rates have been increasing in recent decades. Its main way of transmission is sexual contact, followed by vertical transmission, blood transfusion and direct contact with contaminated blood. It is a multisystemic disease, whose study covers all medical specialties. In rare cases, syphilis can affect the kidney, most commonly with isolated proteinuria and nephrotic syndrome.

\section{CASE REPORT}

We report the case of a 33-year-old female, married, nulliparous, previously hypertensive, who initially presented symmetric and additive polyarthritis with morning stiffness. She

evolved with multiple mononeuritis and a chronic ulcer in lower limb. The patient also had abnormal tests, including urinalysis displaying hematuria and proteinuria, 24-hour proteinuria of $3.4 \mathrm{~g}$ and worsening renal function, data that led to hospital admission for diagnostic and therapeutic approach. Research for autoimmune and infectious diseases was performed. Patient had negative FAN, $102 \mathrm{U} / \mathrm{mL}$ anti-SSA, and p-ANCA in low titers. Diagnostic of syphilis was made, with VDRL 1:4 and a positive FTA-abs. The patient received standard treatment for tertiary syphilis (three applications of 2,400,000 IU Penicillin G Benzathine at one-week intervals for her and her partner). Simultaneously, a pulsetherapy with methylprednisolone $1 \mathrm{~g} /$ day for 3 days and cyclophosphamide $1 \mathrm{~g}$ was administered while awaiting renal and minor salivary gland biopsies. Patient evolved with improvement of renal function and resolution of the joint involvement. Following the investigation, minor salivary gland biopsy was negative, and renal biopsy showed focal and segmental glomerulosclerosis (FSGS) with severe interstitial fibrosis and deposits of C3c, fibrinogen, IgM, IgG and Kappa in immunofluorescence.

\section{CONCLUSION}

Although the authors believe in syphilis as the cause of FSGS, it is not possible to affirm this association, since the patient obtained clinical improvement after simultaneous treatment of infection and autoimmunity. Lupus, Sjögren's syndrome and vasculitis are very unlikely etiologies in the present case. Long-term follow-up should help to better define the cause of the glomerulosclerosis. 